\title{
Review on Mechanical Properties of Cement Mortar Enhanced with Nanoparticles
}

\author{
D. Nivethitha ${ }^{1}$, S. Srividhya ${ }^{2}$, S. Dharmar ${ }^{3}$ \\ ${ }^{1,2}$ P.G Scholars, Department of Civil Engineering, P.S.R. Engineering College, Sivakasi. (India) \\ ${ }^{3}$ Associate Professor, Department of Civil Engineering, P.S.R. Engineering College, Sivakasi (India)
}

\begin{abstract}
Cement mortar is a building composite produced by mixing cement and a selection of fine aggregates with a specified amount of water. The mortar can be used for a number of applications, such as plastering over bricks or other forms of masonry. Cement mortar has a low strength and durability, so it is not efficiently used for aggressive environment, such as chemical industries, offshore structures, power plants etc. Cement is a chief component of production of mortar. The leadingproblematic of global warming is $\mathrm{CO}_{2}$ emission, throughout the cement manufacture. To overcome the above shortcomings, nanoparticles are added. If nanoparticles are combined with cement based building material, the new material might possess some outstanding properties. When nano-scale particles are integrated in cement mortar or in concrete, the products with different properties will be created. Nanoparticles can accelerate cement hydration due to their high activity and also they act as a nano-filler, compacting the microstructure, and consequently increase

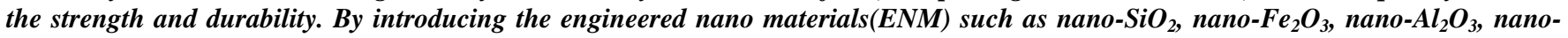
$\mathrm{CuO}$, nano-TiO ${ }_{2}$, etc., and nano structured waste materials which can increase the mechanical properties and durability of the concrete and mortar.
\end{abstract}

Keywords: Cement mortar, aggressive environment, Cement, $\mathrm{CO}_{2}$, Nanoparticles, ENM.

\section{Introduction}

Amount of $\mathrm{CO}_{2}$ produced from the worldwide manufacture of Ordinary Portland Cement (OPC) corresponds to approximately $7 \%$ of the total releases into the Earth's atmosphere. The productions of $\mathrm{CO}_{2}$ in cement and concrete manufacturing can be controlled by the integration of Green concrete in the mix design, without reducing the quality of the ending product. One of the solutions for this worldwide concern is the use of supplementary cementitious materials as an additional for cement. The mortar can be used for a number of uses, such as plastering over bricks or other forms of masonry. Cement mortar has a low strength and durability, so it is ineffectively used for aggressive environment, such as chemical industries, offshore structures, power plants etc. To overcome the above downsides, nanoparticles are added.

The construction region burdens products like cement, steel, paints, insulation materials, window glass and many others. Nano materials are incorporated into those products to improve their properties or to develop new functionalities. The mission for sustainable development and the construction of green buildings in architecture also effects the innovation of products that exploit nano material properties. Therefore it can be said that nanomaterials are used either

- To improve the quality of current products, or

- To originate by developing original functionalities in conventional products or through the creation of new products and applications.

Exceptional properties observed at the nanoscale are intended to be introduced to construction ingredients. A special case are Carbon Nanotubes (CNT), which provide a strength 35 times greater to concrete, which make it appropriate to be used in concrete structures. So far it can be said that nanotechnology development could contribute to achieve some of the following final goals: Grow stronger concrete structures, Generate enhanced environments, Defend the appearance and durability of structures, Reduce energy and other capitals consumption.

\section{Objective}

To study the mechanical properties of cement mortar enhanced with different nanoparticles.

\section{Literature Survey}

Sattawat Haruehansapong et.al, [1] presents the compressive strengths of cement mortars containing nanosilica (NS) with numerous sizes of 12, 20 and $40 \mathrm{~nm}$ then compared with cement mortar with silica fume (SF). Tested results showed that NS considerably improved compressive strength of cement mortar. Cement mortar enclosing NS $40 \mathrm{~nm}$ gave higher compressive strength related with NS 12 and $20 \mathrm{~nm}$. By changing the replacement contents of $3 \%, 6 \%, 9 \%$ and $12 \%$ NS through weight of cement, the optimum replacement content was $9 \%$ for all NS particle sizes and SF. NS particles existing high pozzolanic activity and might fill up pores, resulting in homogeneous and dense microstructures.

Hui Li et.al, ${ }^{[7]}$ studied the mechanical properties of nano$\mathrm{Fe}_{2} \mathrm{O}_{3}$ and nano- $\mathrm{SiO}_{2}$ cement mortars were experimentally studied. The experimental results presented that the compressive and flexural strengths measured at the $7^{\text {th }}$ day and $28^{\text {th }}$ day of the cement mortars mixed with the nanoparticles were higher than that of a plain cement mortar. The compressive and flexural strength of the cement mortars with nano- $\mathrm{SiO}_{2}$ and with nano- $\mathrm{Fe}_{2} \mathrm{O}_{3}$ were together higher than that of the plain cement mortar with the same w/b. The SEM observations also exposed that the nano-particles were not only acting as a filler, but also as an activator to support 


\section{International Journal of Science and Research (IJSR) \\ ISSN (Online): 2319-7064}

Index Copernicus Value (2013): 6.14 | Impact Factor (2014): 5.611

hydration proves and to improve the microstructure of the cement paste if the nano-particles were uniformly spread.

Mounir Litifi et.al, ${ }^{[5]}$ focused on the properties of cement mortars with nano- $\mathrm{SiO}_{2}$ were experimentally studied. Nanoparticles of silica amorphous were combined at a rate of 3 and $10 \%$ by weight of cement. The compressive strengths of different mortars increase with the increasing of the amount of nano- $\mathrm{SiO}_{2}$. The influence of nano- $\mathrm{SiO}_{2}$ on consistency and setting time are dissimilar. Nano- $\mathrm{SiO}_{2}$ creates cement paste thicker and accelerates the cement hydration process. Compressive strengths increase with growing the nano- $\mathrm{SiO}_{2}$ content. It looks due to the action of nano- $\mathrm{SiO}_{2}$ as an activator to promote hydration proves and to increase the microstructure of the cement paste if the nano-particles were uniformly dispersed. Fig 1 shows the Compressive strength of cement mortar enhanced with NS.

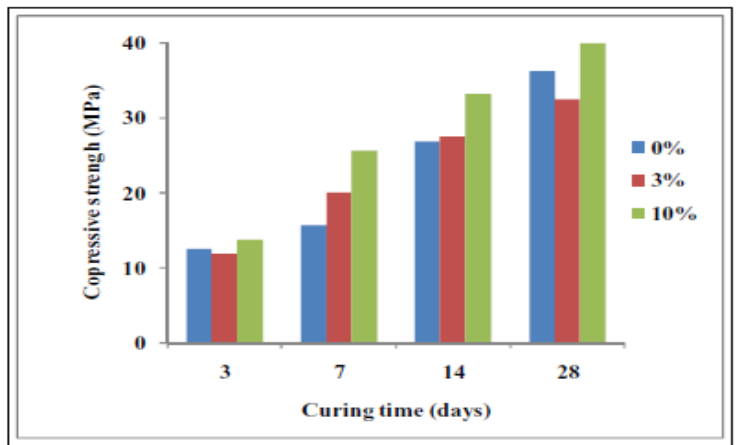

Figure 1: Relationship between compressive strength and curing time of mortar

N.Abdoli Yazadi et.al, ${ }^{[2]}$ study has been done on the compressive and tensile strength of cement mortar having $\mathrm{Fe}_{2} \mathrm{O}_{3}$ nanoparticles in the quantities of 1,3 and $5 \%$ by weight of cement. The results show that the mechanical properties of samples having $1 \%$ and $3 \% \quad \mathrm{Fe}_{2} \mathrm{O}_{3}$ nanoparticles are required than the ordinary cement mortar. With respect to the experimental results of tensile and compressive strength it is expected that adding of $\mathrm{Fe}_{2} \mathrm{O}_{3}$ nanoparticles up to $3 \%$ by weight of cement can act as a filler for strengthening the micro structure of cement and also reduces the amount and size of $\mathrm{Ca}(\mathrm{OH})_{2}$ crystals and fill the voids of C-S-H gel structure and finally structure of hydrated product is compacted and denser. With the increase of nanoparticles quantity up to $5 \%$, reduction in nanoparticles distance and $\mathrm{Ca}(\mathrm{OH})_{2}$ crystal due to limited space cannot grow to suitable size. This factor along with the agglomerated nanoparticles causes the mechanical properties of the sample $5 \mathrm{NF}$ is inferiorto the ordinary mortar sample.

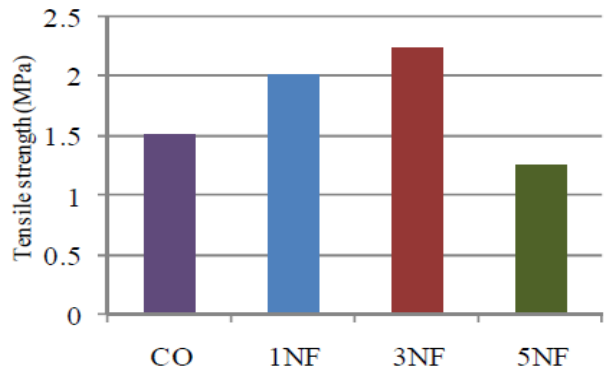

Figure 2: Tensile strength of sample

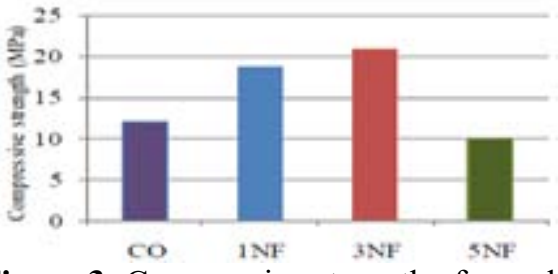

Figure 3: Compressive strength of sample

M.Aly et.al, ${ }^{[8]}$ studied the Green glass powder $(5-50 \%$ by cement weight) and NC powder (2.5\% by cement weight) were tried for possible employment as cement replacement in cementitious materials. Founded on flexural and compressive strength, the ASR test and the $\mathrm{CH}$ content of the plain, glass powder, and $\mathrm{NC}$ /glass powder cement mortars, it was observed that the replacement of cement by $20 \mathrm{wt} \%$ glass powder and $2.5 \mathrm{wt} \% \mathrm{NC}$ particles is possible in a cementitious system. Associated to the control mix without glass, high fracture energy, flexural and compressive properties can be attained when using up to $50 \%$ green glass powder as a cement replacement after 28 days of hydration.

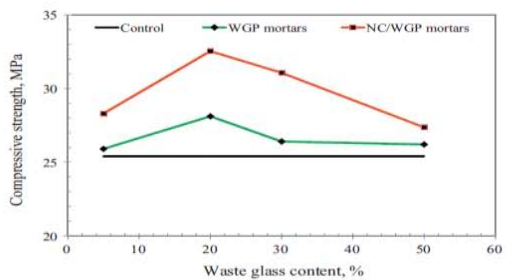

Figure 4: Compressive strength of mortars after $28^{\text {th }}$ days.

Meral Oltulu et.al, ${ }^{[3]}$ showed an experimental study on single and combined effects of nano- $\mathrm{SiO}_{2}$, nano- $\mathrm{Al}_{2} \mathrm{O}_{3}$ and nano- $\mathrm{Fe}_{2} \mathrm{O}_{3}$ fine particleson compressive strength and capillary permeability of cement mortar havingsilica fume. It was determined from the experimental results that the type and quantity of nano the powders, and mortar making methods had a major effect on the fresh and hardened properties of cement mortars. The nano-powders used singly or in combination improved the $28^{\text {th }}$ day compressive strength of silica fume-containing mortars by up to $27 \%$, with the exception of nano- $\mathrm{SiO}_{2}$ powder used at a proportion of $2.5 \%$. Though, the compressive strength standards fluctuated at early and later ages. The best results for compressive strength and capillary permeability at the end of day 180 were gained with $1.25 \%$ nano- $\mathrm{Al}_{2} \mathrm{O}_{3}$ powder in single uses, $0.5 \%$ nano- $\mathrm{SiO}_{2}+$ nano- $\mathrm{Al}_{2} \mathrm{O}_{3}$ powders in dual combinations. However, it was determined that the interface between the powders used in binary and ternary combinations led to harmful effects on the physicalmechanical properties of the mortars. For this reason, nano$\mathrm{Al}_{2} \mathrm{O}_{3}$ powder and single use were primarily recommended in cases where agrowth in the performance of cement-based composites is desired. The conclusions of the experiments suggested the improvement in the mechanical and physical properties of mortars was affected by the rise in pozzolanic activity induced by the promising influence of the powders rather than the filler effect.

M.J. Pellegrini-Cervantes et.al $^{[4]}$ have conducted experimental study on Corrosion Resistance, Porosity and Strength of blended Portland Cement Mortar comprising 


\section{International Journal of Science and Research (IJSR) \\ ISSN (Online): 2319-7064}

Index Copernicus Value (2013): 6.14 | Impact Factor (2014): 5.611

Rice Husk Ash and Nano- $\mathrm{SiO}_{2}$. Studies of compressive strength, total porosity in open pore and accelerated corrosion test with impressed voltage $12.0 \mathrm{~V}$ in mortars were completed, using replacements of OPC by $10-30 \%$ of RHA and $1.00-2.00 \%$ of $\mathrm{nSO}$ in single and simultaneous use. For the purpose of determining the performance of the OPC replacements on the properties of the mortar, resulting in the most effective use with immediate decrease in porosity up to $5.7 \%$ and increased compressive strength and corrosion of $7.8 \%$ and $51.1 \%$ respectively. The use of superplasticizer expedited the making of mixtures with RHA and $\mathrm{nSO}$, but affected the physical and chemical properties of hardened mortar. Replacement of OPC by RHA and nSO in simultaneous use in mortars with plastic consistency present the advantage of improving physical and mechanical properties in replacements up to $20 \%$ RHA, due to the synergistic effect of RHA-nSO and porosity - compressive strength.

M.S.Morsy, et.al, ${ }^{[6]}$ studied to evaluate the effects of $\mathrm{NC}$ on rate of cement hydration, strength development of mortar. The nano-clay used in this study was nano-kaolin. The nanometakaolin (NMK) was prepared by thermal activation of kaolin clay for 2 hours at $750^{\circ} \mathrm{C}$. The blended cement used in this investigation consists of ordinary Portland cement and nano-metakaolin. The blended cement mortar was prepared using cement-sand ratio of $1: 2$ by weight with water-binder ratio as 0.5 . Compressive and tensile strength of the cement mortars with NMK is developed than that of the plain cement mortar with the same w/b ratio. The improvement of tensile strength was $49 \%$ above control mortar; while the enhancement of compressive strength was $7 \%$ at $8 \%$ NMK replacement.

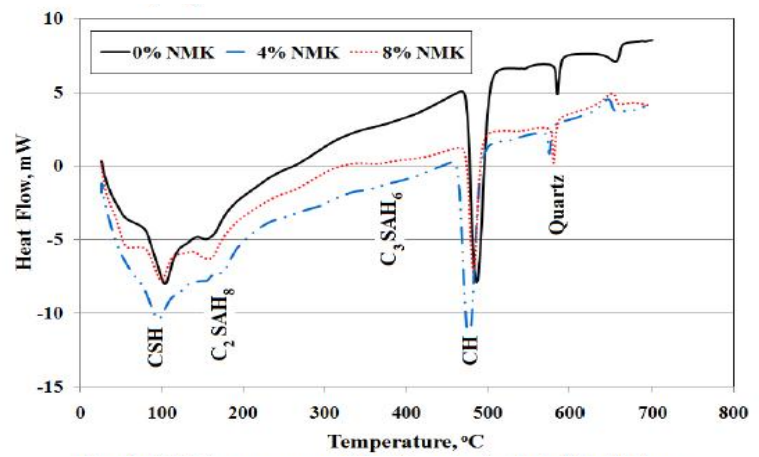

Figure 5: DSC thermo grams of NMK mortar hydrated for 28 days

M. Aly et.al, ${ }^{[10]}$ Studied the effect of partial replacement of Ordinary Portland cement (OPC) by finely ground waste glass powder (WG) and nano clay particles (NC) on the mechanical performance and durability of flax fibre reinforced cement composites (FRC). Test were intended to study the alkali-silica reaction (ASR), X-ray diffraction analysis (XRD), differential thermal analysis (DTA) and the mechanical performance of the composites. Additionally, the durability of the composites aged under wetting and drying cycles are presented. The result in Figure 6, Figure 7 and Figure 8 represents a graph for fracture energy test, flexural strength test and impact strength test respectively. From the result it is concluded that combined use of nano clay particles (NC) and ground waste glass powder (WG) can growth the compressive strength and durability. The addition of NC particles has great potential to accelerate the pozzolanic reaction. It seems that their nano size allows them to react more readily with the $\mathrm{CH}$, thereby increasing $\mathrm{CSH}$ conversion at 28 days of hydration. The hybrid combination of $\mathrm{NC}$ and $\mathrm{WG}$ was found to be a very effective way to use ground waste glass as a cement replacement and to achieve good performance at reasonable cost and Replacement of OPC by $20 \%$ ground glass powder and $2.5 \% \mathrm{NC}$ in flax fibre cement mortars increases fracture, bending and impact properties after 28 days of hydration.

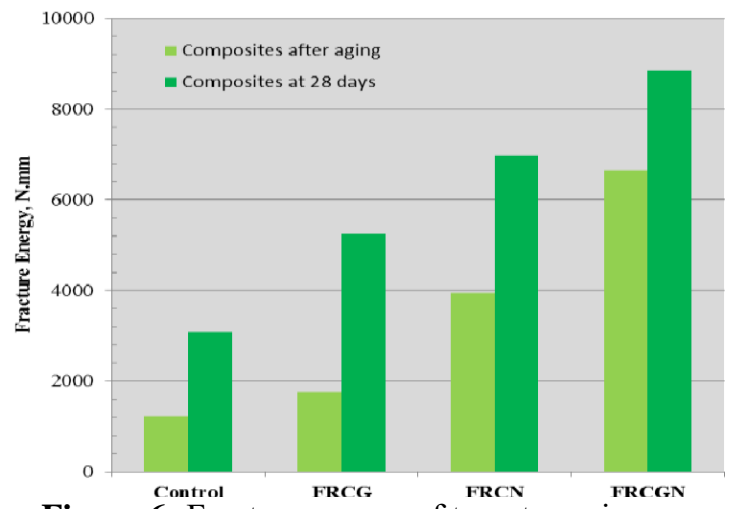

Figure 6: Fracture energy of target specimens

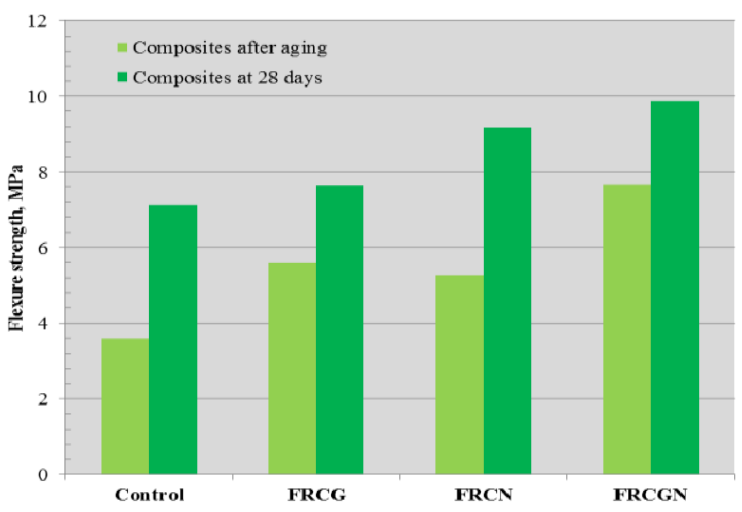

Figure 7: Flexural strength of target specimens.

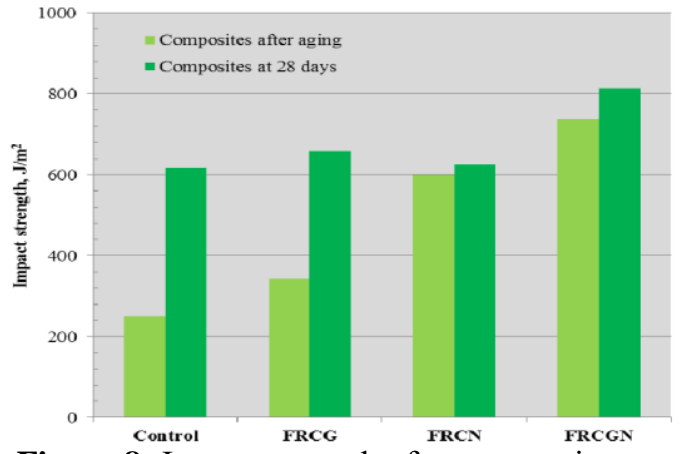

Figure 8: Impact strength of target specimens

Wen-Yih Kuo et.al, ${ }^{[9]}$ investigated the addition of organomodified montmorillonite (OMMT) particles to cement mortars can enhance their microstructure as well as mechanical properties. On the basis of MIP measurements, it is found that the pore size circulations of cement mortars are affected expressively by the introduction of OMMT particles. For cement mortars reinforced with less than $2 \%$ well-dispersed OMMT particles, the space of capillary pores is partially filled by OMMT particles and thus their total porosity and the volume of intermediate pores between 0.1 $\mathrm{lm}$ and $0.2 \mathrm{~lm}$ reduced. Nevertheless, the volume of larger 


\section{International Journal of Science and Research (IJSR) \\ ISSN (Online): 2319-7064}

Index Copernicus Value (2013): 6.14 | Impact Factor (2014): 5.611

pores is slightly increased and the size distribution and volume of smaller pores are less affected as compared to plain cement mortars.

\section{Conclusion}

A number of researches conducted on nanoparticles as an admixtures in mortar the following outcomes measured are as follows,

- The addition of nano silica and nano silica fume rise the mechanical properties and decrease initial \& final setting time.

- Nano $\mathrm{Fe}_{2} \mathrm{O}_{3}$ in the quantities of $1 \& 3 \%$ by weight of cement increase the compressive, flexural and impact strength of mortar.

- Nano clay can improve the mechanical and durability of high performance mortar.

- Nano structured waste materials such as ground waste glass powder, rise husk ash are also improve the mechanical, thermal and durability properties of the mortar.

- Combined NS, NA and NF can surge the compressive strength and durability.

- Nano particle can also act as a filler material, which can decrease the voids and permeability of mortar.

- Nano particles also improve the hydration process and reduce setting time of mortar.

- Addition of nanoparticle leads to increase the short term and long term strength.

- Nano structured waste materials such as cement kiln dust, glass powder and copper slag increase the compressive strength and decrease the porosity, shrinkage.

\section{References}

[1] Sattawat Haruehansapong et.al, "Effect of the particle size of nanosilica on the on the compressive strength and the optimum replacement content of cement mortar containing nano- $\mathrm{SiO}_{2}$ " Journal of Construction and Building Materials 50 (2014) 471-477.

[2] N.Abdoli Yazadi et.al, "To study the effect of adding $\mathrm{Fe}_{2} \mathrm{O}_{3}$ nanoparticles on the morphology properties and microstructure of cement mortar"Life Science Journal, 2011.

[3] Meral Oltulu et.al, "Effect of nanosilica addition on the fresh properties and shrinkage of mortar with fly ash and super plasticizer" Journal of Construction and Buildings Materials 84 (2015) 269-276.

[4] M.J.Pellegrini-Cervantes et.al, "Corrosion Resistance, Porosity and Strength of Blended Portland Cement Mortar Containing Rice Husk Ash and Nano-SiO 2 " Journal of Electrochemist. Sci., 8 (2013) 10697 10710.

[5] Mounir Litifi et.al, "Experimental study of the effect of addition of nano silica on the behaviour of cement mortars"Journal of Procedia Engineering 10 (2011) 900-905.

[6] M. S. Morsy et.al, "Effect of Nano-clay on Mechanical Properties and Microstructure of Ordinary Portland Cement Mortar" International Journal of Civil \& Environmental Engineering IJCEE-IJENS Vol:10 No:01.
[7] Hui Li et.al, "Microstructure of cement mortar with nano-particles"Journal of Composite: part B 35 (2004) 185-189.

[8] M.Aly et.al, "Effect of nano clay particles on mechanical, thermal and physical behaviours of wasteglass cement mortar"Journal of Materials Science and Engineering A 528 (2011) 7991-7998.

[9] Wen-Yih Kuo et.al, "Evaluation of strengthening through stress relaxation testing of organo-modified montmorillonite reinforced cement mortars" A Journal of Construction and Building Materials.

[10] M. Aly et.al, "Effect of Nano-Clay and waste glass powder on the properties of flax fibre reinforced mortar" ARPN Journal of Engineering and Applied Sciences. 